\title{
A Quantitative Analysis of the Effectiveness of a Field Visit on the Environmental Knowledge, Attitudes, and Behavior of Youth
}

\author{
Mark C. Mifsud \\ University of Malta, Msida, Malta
}

\begin{abstract}
Young people are becoming more detached from nature through a number of causes, including their increased use of digital media. This detachment from nature results in a lowering in the sense of ownership of the land and its resources, and subsequently, results in less motivation to conserve it. In order to reverse such behaviours and attitudes, a new programme termed "Lifelong Learning through Nature (LLN)" was devised. This study is an analysis of the LLN programme and its potential of making links among outdoor learning, fieldwork, and education for sustainable development. These results shed light on the effectiveness of the programme in influencing knowledge and attitudes, and in turn, lead to formulate a way forward in the programme's evolution. Outdoor education is an essential element of education for sustainable development (ESD), which is key to address the current situation for a sustainable future. The data is collected through an extended questionnaire from a number of different schools in the Maltese islands, which is analysed through Statistic Package for Social Science (SPSS). The results reveal a great sense of detachment in the young students, and eventually, a greater sense of pointlessness in the older students. This study reveals that the field visit does have an influential role in the knowledge and attitudes of school children towards nature. This study continues to uphold the vision that outdoor education should be considered as a main activity, which involves and results in ESD. In response to these findings, a model illustrating the emerging links between the field visit programme and various factors is presented. This paper directly illustrates how university research in teamwork with non-governmental organisations can impact the local community. Also, the study will be useful to anyone who is interested in carrying out effective programs and research in the links between ESD and outdoor education.
\end{abstract}

Keywords: field visit, education for sustainable development (ESD), quantitative methods, outdoor education

\section{Introduction}

This reseach was developed in order to study the effectiveness and analyse the fieldwork component of the a collaborative educational programme termed "Lifelong Learning through Nature (LLN)," which is partnership project among BirdLife Malta, the Ministry for Education and Employment (Malta), the Royal Society for the Protection of Birds (UK), BirdWatch Ireland, and the Polish Society for the Protection of Birds.

The study included the following main objectives:

1. To analyse the current perceptions of youth with regard to the environment;

2. To study the effectiveness of the resources produced by the programme;

Mark C. Mifsud, Ph.D., Dr., Centre for Environmental Education Research (CEER), University of Malta. 
3. To study the effectiveness of the LLN programme in moulding current youth perceptions;

4. To study whether the programme has an impact on student understanding or not;

5. To study possible links to an increased connection between "nature and health" and "well-being and education";

6. To use the feedback in an ongoing way to improve the delivery and effectiveness of the programme.

The fieldwork programme is a new environmental education programme being piloted by BirdLife Malta. A study on such a programme that the young students and teachers are involved will be of benefit to the environment in this particular geographic location. Additionally, not much is known about the perceptions of young people in the Maltese islands. Although published research (Mifsud, 2011) indicated and highlighted a number of main processes that are responsible for the acquisition and development of environmental perspectives in young people in Malta, including outdoor education. These processes can foster a sense of environmental responsibility, but action towards sustainable development in a small island state still need to be investigated.

\section{Youth and Environmental Perceptions}

The perception of environmental issues, as represented by the environmental actions, attitude, and knowledge of young people is of great importance for a number of reasons as the following:

1. Knowing what students think about environmental issues will help to establish better pro-environmental education among them (Pawlowski, 1996);

2. The involvement of youth in environment and development decision-making and in the implementation of programmes is critical to the long-term success of Agenda 21* (United Nations Conference on Environment and Development [UNCED], 1992);

3. In the near future, they will have a great influence on the running of business (Bynoe, 2005);

4. College students are an important segment of society and warrant attention in terms of studying environmental attitudes, as they have been the leading crusaders in the modern environmental movement. For example, the huge success of Earth Day (1970) in the USA was largely attributed to college students when approximately 1,500 colleges participated in the campaign (Thapa, 2001);

5. As most environmental attitude studies focus on adults, Gough (1999) stressed the need for studies of environmental sensitivity in youth and stated that working with young people who have chosen to be environmental activists/educators is much more meaningful for replicability of significant life experiences than working with old people;

6. Education for sustainable development (ESD) is now specifically mentioned in the National Curriculum Framework (NCF) as a cross curricular theme and teachers will be given the opportunity to introduce ESD concepts in each lesson. This is crucial in order to put ESD on top of its national agenda as proposed during the United Nations (UN) Decade of ESD in 2005-2014.

\section{Overarching Research Framework}

This research moves beyond the quantitative/qualitative debate as both types of research are useful. The aim of the methodology in this research is to maximize the strength of the traditional qualitative and

\footnotetext{
* Agenda 21 is a non-binding action plan of the United Nations with regard to sustainable development.
} 
quantitative methods, and minimize their weaknesses. Mixed methods is therefore an ecotone in between two ecosystems. It is the grey area in between the black and white continuum.

The methodology for this study included a mixed method approach employing a combination of empirical/analytical and constructivist/interpretivists approaches. This complementary research activity promotes a multi-paradigm research, in which each methodological approach can contribute in meeting valid research goals of environmental education (Connell, 1997). Nonetheless, the quantitative study only is considered within the parameters of this paper.

The quantitative data was collected through the use of a number of questionnaires, which were drafted following consultation with existing questionnaires already used in the field (Mifsud, 2012). The questionnaires were piloted, and eventually, the delivery and collection of the questionnaires took place in the first three months of the year 2016. The questionnaires allowed for the collection of a large amount of data from a statistically significant sample of the student population in the Maltese islands. The sample was a stratified random sample and included 329 primary students (166 males and 191 females) and 233 secondary students (147 males and 86 females).

The questionnaire examined a number of different areas as the following:

1. Socio-demographic characteristics;

2. The participants' experience of the LLN programmes;

3. The strengths and weaknesses of the visit;

4. Thoughts, feelings, and perceptions about the nature watch visit;

5. Sources of environmental information and their reliability.

The data was collected, and eventually, inputted into a number of Statistic Package for Social Science (SPSS) spreadsheets. Another questionnaire with open-ended questions was distributed to the teachers who did the nature reserve watch visit with their students. In this case, the sample amounted to all the teachers who were involved bringing the teacher sample to 57. A number of descriptive and inferential statistical tests were conducted.

\section{The Analysis}

Quantitative data was collected through three questionnaires and addressed to primary and secondary students. The questionnaires were drafted through the combination of a number of synergistic factors. The questionnaire examined a number of different areas that focused on uncovering the importance or otherwise of the LLN programme. The questionnaire also obtained information on socio-demographic characteristics of youth. The results presented here have been achieved through stratified random sampling, which attempt to portray a statistically significant sample of the young people of the Maltese islands and as such can be extrapolated to the whole population of young people on the islands.

\section{Demographics of Participating Young Students}

The sample of the quantitative study consisted of 329 primary students, include 166 males and 191 females (see Table 1), and 233 secondary students, include 147 males and 86 females (see Table 2) 
Table 1

Gender of Primary Students

\begin{tabular}{llccc}
\hline Gender & Frequency & Percentage (\%) & Valid percentage (\%) & Cumulative percentage (\%) \\
\hline Boy & 166 & 50.5 & 50.5 & 50.5 \\
Girl & 163 & 49.5 & 49.5 & 100.0 \\
Total & 329 & 100.0 & 100.0 & 100.0 \\
\hline
\end{tabular}

Table 2

Gender of Secondary Students

\begin{tabular}{lcccc}
\hline Gender & Frequency & Percentage (\%) & Valid percentage (\%) & Cumulative percentage (\%) \\
\hline Boy & 86 & 36.9 & 36.9 & 36.9 \\
Girl & 147 & 63.1 & 63.1 & 100.0 \\
Total & 233 & 100.0 & 100.0 & \\
\hline
\end{tabular}

The age of students varied from the minimum of 7-year-old up to a maximum of 16-year-old. The majority of students had either 7-year-old, 8-year-old, or 14-year-old (see Tables 3 \& 4).

Table 3

Age of Primary Students

\begin{tabular}{lcccc}
\hline Age & Frequency & Percentage (\%) & Valid percentage (\%) & Cumulative percentage (\%) \\
\hline 7-year-old & 121 & 36.8 & 36.8 & 36.8 \\
8-year-old & 106 & 32.2 & 32.2 & 69.0 \\
9-year-old & 54 & 16.4 & 16.4 & 85.4 \\
10-year-old & 32 & 9.7 & 9.7 & 95.1 \\
11-year-old & 16 & 4.9 & 4.9 & 100.0 \\
Total & 329 & 100.0 & 100.0 & \\
\hline
\end{tabular}

Table 4

Age of Secondary Students

\begin{tabular}{lcccc}
\hline Age & Frequency & Percentage $(\%)$ & Valid percentage $(\%)$ & Cumulative percentage $(\%)$ \\
\hline 11-year-old & 23 & 9.9 & 9.9 & 9.9 \\
12-year-old & 29 & 12.4 & 12.4 & 22.3 \\
13-year-old & 38 & 16.3 & 16.3 & 38.6 \\
14-year-old & 84 & 36.1 & 36.1 & 74.7 \\
15- and 16- year-old & 59 & 25.3 & 25.3 & 100.0 \\
Total & 233 & 100.0 & 100.0 & \\
\hline
\end{tabular}

Malta is traditionally subdivided into three major regions and Gozo, with their particular demographics. The North is thought of as being the region, in which the higher social class and more educated people live. In fact, a town, like Swieqi, in the North of the island has $25 \%$ population who achieved a tertiary level of education, while Marsa in the centre has one-sixth of its population, which are still illiterate. Alarmingly, one in every 20 adolescents aged 10-19 in Bormla and Birgu in the south is illiterate (Government of Malta, 2005).

Nonetheless, lately a large number of people are moving from one region to the other especially as new villages and towns, like Marsascala, in the South are breaking with this tradition. In fact, Marsascala has 19\% 
population that has attained a post-secondary level of education putting the town in first place in this area (Government of Malta, 2005). Tables 5 and 6 indicate the geographic region, in which participants reside. Due to the schools participating in the study, the primary and secondary samples had a small number of both students residing in the North and Gozo, and 10 secondary students did not answer this question.

Table 5

Geographic Region of Primary Participants

\begin{tabular}{lcccc}
\hline Region & Frequency & Percentage (\%) & Valid percentage (\%) & Cumulative percentage (\%) \\
\hline South & 147 & 44.7 & 44.7 & 44.7 \\
Central & 146 & 44.4 & 44.4 & 89.1 \\
North & 14 & 4.3 & 4.3 & 93.3 \\
Gozo & 22 & 6.7 & 6.7 & 100.0 \\
Total & 329 & 100.0 & 100.0 & \\
\hline
\end{tabular}

Table 6

Geographic Region of Secondary Participants

\begin{tabular}{|c|c|c|c|c|c|}
\hline & Region & Frequency & Percentage $(\%)$ & Valid percentage (\%) & Cumulative percentage (\%) \\
\hline \multirow{5}{*}{ Valid } & South & 105 & 45.1 & 47.1 & 47.1 \\
\hline & Central & 76 & 32.6 & 34.1 & 81.2 \\
\hline & North & 18 & 7.7 & 8.1 & 89.2 \\
\hline & Gozo & 24 & 10.3 & 10.8 & 100.0 \\
\hline & Total & 223 & 95.7 & 100.0 & \\
\hline \multirow{2}{*}{ Missing } & System & 10 & 4.3 & & \\
\hline & Total & 233 & 100.0 & & \\
\hline
\end{tabular}

\section{Experiences in the Nature Watch Reserve Visit}

The main question in both primary and secondary students' questionnaire asked them to rate their experience of the nature watch reserve visit on a 5-point Likert scale. The results were positive in their majority with all the statements achieving a mean rating exceeding 4 on a scale from 1-5 $(1$ = "Strongly disagree," $2=$ "Disagree," 3 = "Not certain," 4 = "Agree," and 5 = "Strongly agree") for primary students and positive but at a slightly lower level for secondary students (see Table 7).

Table 7

Nature Watch Reserve Visit Experience for Primary Students

\begin{tabular}{llllll}
\hline Statements & $N$ & Minimum & Maximum & Mean & Std. deviation \\
\hline The nature watch reserve visit was interesting & 329 & 3 & 5 & 4.75 & 0.536 \\
I enjoyed the visit & 329 & 1 & 5 & 4.76 & 0.554 \\
The teachers on site were good & 329 & 1 & 5 & 4.77 & 0.560 \\
The materials and handouts were good & 329 & 1 & 5 & 4.40 & 0.891 \\
The place was great & 329 & 2 & 5 & 4.74 & 0.634 \\
I felt safe outside & 329 & 1 & 5 & 4.15 & 1.000 \\
The visit helped me in school subjects & 329 & 1 & 5 & 4.38 & 0.965 \\
I learned a lot in the outing & 329 & 1 & 5 & 4.65 & 0.682 \\
I cared more about nature following the visit & 329 & 1 & 5 & 4.59 & 0.865
\end{tabular}


Table 8

Nature Watch Reserve Visit Experience for Secondary Students

\begin{tabular}{lllll}
\hline Statements & \multicolumn{3}{c}{$N$} & Std. deviation \\
\cline { 2 - 4 } & Valid & Missing & Mean & 0.853 \\
The nature watch reserve visit was interesting & 233 & 0 & 4.10 & 0.911 \\
I enjoyed the reserve visit & 233 & 0 & 3.96 & 0.795 \\
The teachers on the site were good & 233 & 0 & 4.24 & 0.854 \\
The materials and handouts were good & 233 & 0 & 4.09 & 0.892 \\
The place was great & 233 & 0 & 4.10 & 0.974 \\
I felt safe outside & 233 & 0 & 4.11 & 0.963 \\
The visit helped me in school subjects & 233 & 0 & 3.94 & 0.931 \\
I learnt a lot in the outing & 233 & 0 & 4.00 & 1.041 \\
Group work was good & 233 & 0 & 3.72 & 1.023 \\
Individual work was good & 233 & 0 & 3.77 & 1.003 \\
I cared more about nature following the visit & 233 & 0 & 3.95 & \\
\hline
\end{tabular}

\section{The Best Part of the Programme}

"I increase my knowledge (72.5\%)" and "I care about the environment (57.7\%)" were mentioned as the most important reasons for taking part in the nature watch reserve visit. The importance of linking the visit to relevant knowledge in the visit is highlighted. Nonetheless, there also appears to be a strong emotional factor that should be addressed in such field visits. Other important reasons that were mentioned include national issues: "I have fun (42.3\%)," "To do better in school subjects (39.6\%)," and "I love the activities (28.4\%)."

The mean of the remaining reasons drops significantly. Especially, thought-provoking are the results for the statements that included some sort of achievement or competition, such as "I like to receive an award" (7.7\%). This low response rate seems to indicate that students are more interested in intrinsic motivating factors rather than extrinsic. Programmes can become more effective if this is taken into consideration. Table 9 and Figure 1 illustrate the results obtained from this question.

Analysis of the above data according to gender seems to show that the results are the same for boys and girls for most of the reasons. The main differences between girls and boys appear to be the following two statements: "I have fun $(53.1 \%$ and $36.2 \%$, respectively)" and "To make more friends $(3.7 \%$ and $9.2 \%$, respectively)." Boys seem to be more interested in having "fun" than girls, while real social interaction (although low in both genders) is more sought after by girls (see Table 10).

Table 9

The Best Part of the Programme for Secondary Students

\begin{tabular}{lcc}
\hline Statements & Frequency & Percentage (\%) \\
\hline I like to receive an award & 17 & 7.7 \\
I increase my knowledge & 161 & 72.5 \\
Because of my values & 16 & 7.2 \\
To do better in school subjects & 88 & 39.6 \\
I care about the environment & 128 & 57.7 \\
I love the activities & 63 & 28.4 \\
I have fun & 94 & 42.3 \\
To make more friends & 16 & 7.2 \\
To achieve more as a class & 41 & 18.5 \\
To achieve more as a school & 32 & 14.4 \\
\hline
\end{tabular}




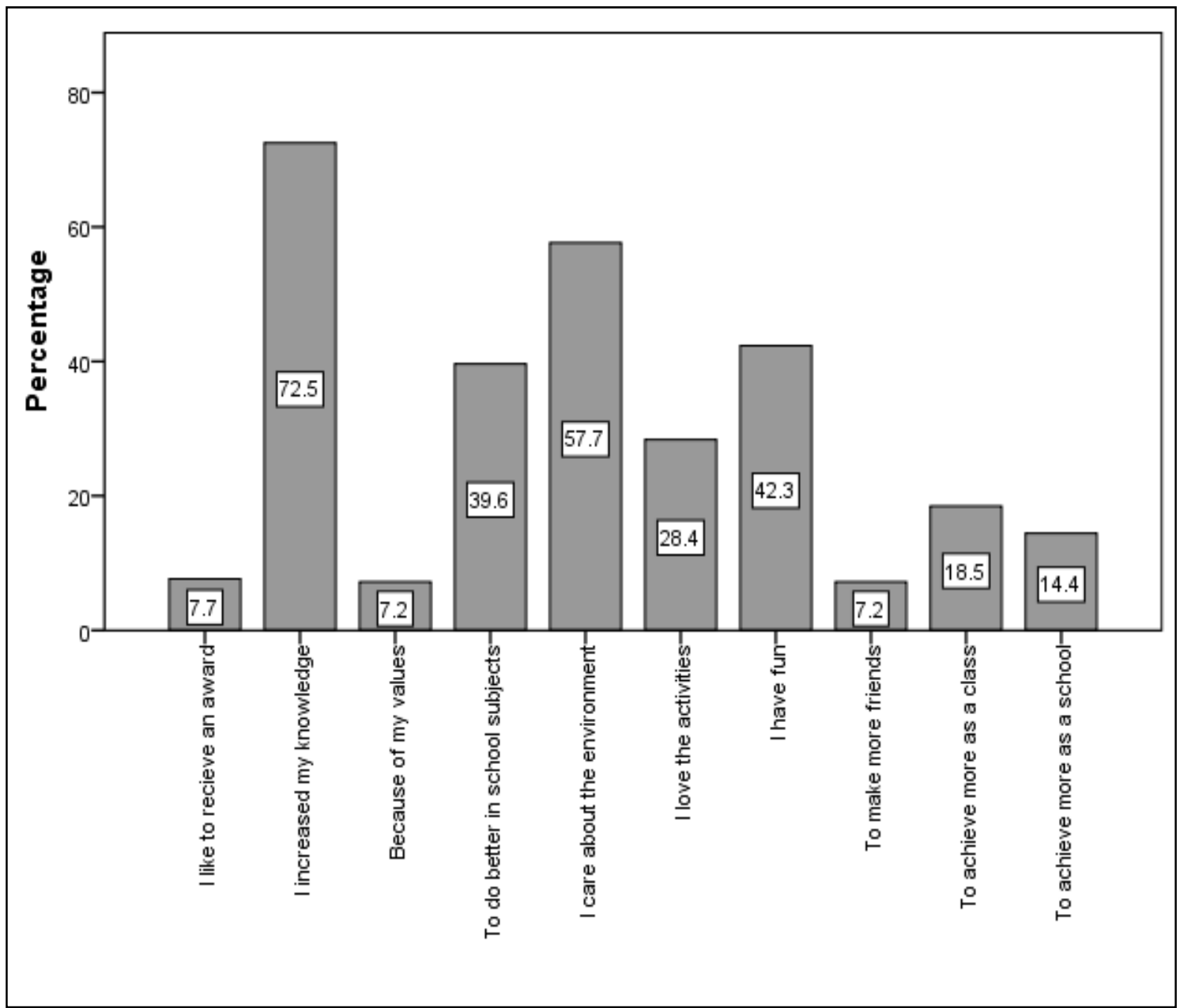

Figure 1. The best part of the programme for secondary students.

Table 10

The Best Part of the Programme for Secondary Girls/Boys

\begin{tabular}{lcc}
\hline \multirow{2}{*}{ Statements } & \multicolumn{2}{c}{ Gender } \\
\cline { 2 - 3 } & Boy (\%) & Girl (\%) \\
\hline I like to receive an award & 6.2 & 8.5 \\
I increase my knowledge & 77.8 & 69.5 \\
Because of my values & 6.2 & 7.8 \\
To do better in school subjects & 35.8 & 41.8 \\
I care about the environment & 54.3 & 59.6 \\
I love the activities & 28.4 & 28.4 \\
I have fun & 53.1 & 36.2 \\
To make more friends & 3.7 & 9.2 \\
To achieve more as a class & 11.1 & 22.7 \\
To achieve more as a school & 17.3 & 12.8 \\
\hline
\end{tabular}

\section{Sources of Information}

The majority of students received some information from all the listed sources. Results show that students receive most information from school $($ Mean $=3.48)$, the Internet $($ Mean $=3.45)$, and the LLN nature visit 
$($ Mean $=3.36)$. Conversely, students obtain the least amount of information from radio (Mean $=1.77)$, Billboards (Mean $=1.78)$, and government agencies (Mean $=1.94)$. The general importance of education in this section was strongly emphasised and the importance of the Internet, school, and the LLN nature visit to a holistic increase in environmental awareness should be studied further. The government should start a review process of the effectiveness or otherwise of its agencies as they appear to be largely invisible to the younger generation with regards to environmental issues (see Table 11).

Table 11

Where do you Get Most Information Regarding the Environment for Secondary Students

\begin{tabular}{|c|c|c|c|c|c|}
\hline & \multicolumn{2}{|c|}{$N$} & \multirow{2}{*}{ Mean } & \multirow{2}{*}{ Std. deviation } & \multirow{2}{*}{ Sum } \\
\hline & Valid & Missing & & & \\
\hline Billboards & 233 & 0 & 1.78 & 0.814 & 415 \\
\hline Books & 233 & 0 & 2.91 & 0.974 & 677 \\
\hline Family & 233 & 0 & 2.71 & 1.012 & 632 \\
\hline Friends & 233 & 0 & 2.51 & 0.947 & 584 \\
\hline Government agencies & 233 & 0 & 1.94 & 0.947 & 453 \\
\hline Internet & 233 & 0 & 3.45 & 0.798 & 805 \\
\hline Magazines & 233 & 0 & 2.10 & 0.967 & 489 \\
\hline National campaigns & 233 & 0 & 2.20 & 1.032 & 512 \\
\hline Non-governmental organisations & 233 & 0 & 2.07 & 1.004 & 483 \\
\hline Radio & 233 & 0 & 1.77 & 0.941 & 412 \\
\hline School & 233 & 0 & 3.48 & 0.726 & 810 \\
\hline Television & 233 & 0 & 2.71 & 1.051 & 631 \\
\hline Dinja Wahda & 233 & 0 & 2.20 & 1.058 & 513 \\
\hline Ekoskola & 233 & 0 & 2.39 & 1.151 & 556 \\
\hline The nature watch reserve visit & 233 & 0 & 3.36 & 0.799 & 784 \\
\hline
\end{tabular}

\section{Inferential Statistics}

In this study, statistical tests were carried out to evaluate the different parameters of the questionnaire in order to find the degree of interactions, if any. More specifically, a number of correlations were carried out with various types of demographic data.

\section{Primary Students}

The results from the questions that concerned the nature watch reserve visit experience reveal that the experience was a very positive one and that there are some differences in the results of the various statements. The results for primary students indicate that "The teachers on site were good (Mean $=4.77)$ " and "I enjoyed the visit (Mean $=4.76)$ " were the top scoring statements, while "I felt safe outside (Mean $=4.15)$ " was the lowest scoring statement. The Friedman test suggests that the difference in statement score is significant and is not attributed to chance since the $p$-value (approximately 0.001 ) is less than the 0.05 level of significance (see Table 12 and Figure 2).

The mean score from the nature watch reserve visit experience was analyzed according to the gender of the young people population to identify any correlation between the two. The mean total scores for females and males appear to be both very positive in all the statements. Further analysis with the Kruskal Wallis test indicates that for most of the statements there is no statistical significance between genders. However, the test 
indicates statistical significance for two statements: "I enjoyed the visit" and "The place was great" since the $p$-value (approximately 0.036 and 0.030 , respectively) is less than the 0.05 level of significance. Therefore, the statistical test indicates a statistically significant relationship between gender and these two statements, suggesting that males enjoyed the visit and the place more than females (see Table 13 and Figure 3).

Table 12

Nature Watch Reserve Visit Experience

\begin{tabular}{lllll}
\hline Experience of nature watch reserve visit & Mean & Std. deviation & Minimum & Maximum \\
\hline The nature watch reserve visit was interesting & 4.75 & 0.536 & 3 & 5 \\
I enjoyed the visit & 4.76 & 0.554 & 1 & 5 \\
The teachers on site were good & 4.77 & 0.560 & 1 & 5 \\
The materials and handouts were good & 4.40 & 0.891 & 1 & 5 \\
The place was great & 4.74 & 0.634 & 1 & 5 \\
I felt safe outside & 4.15 & 1.000 & 1 & 5 \\
The visit helped me in school subjects & 4.38 & 0.965 & 1 & 5 \\
I learned a lot in the outing & 4.65 & 0.682 & 1 & 5 \\
I care more about nature following the visit & 4.59 & 0.865 & & 5 \\
\hline
\end{tabular}

Notes. $X^{2}(8)=294.74 ; p<0.001$.

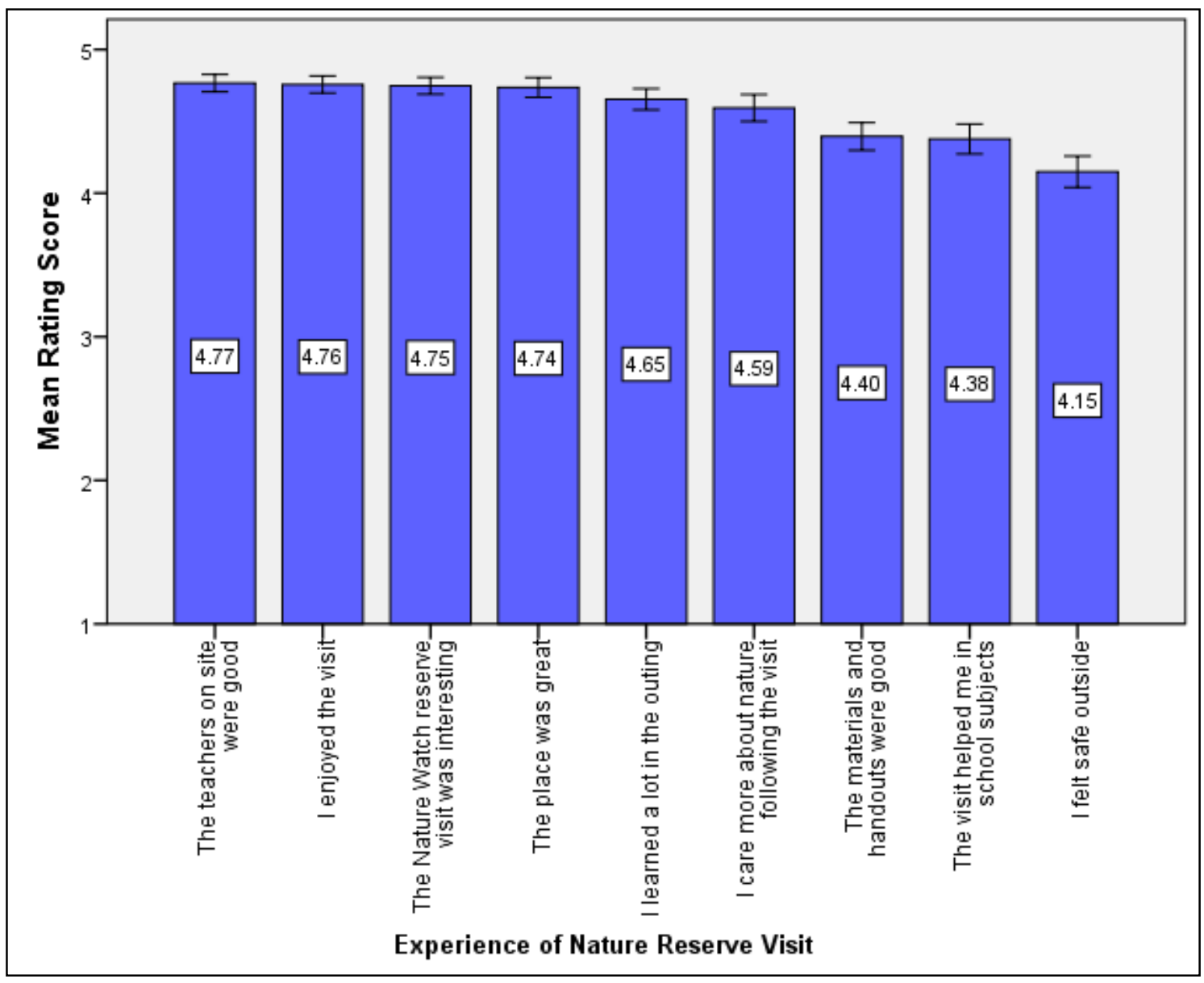

Figure 2. Experience of nature watch reserve visit. 
Table 13

Nature Watch Reserve Visit Experience in Male/Female Comparison

\begin{tabular}{|c|c|c|c|c|}
\hline Experience of nature watch reserve visit & Gender & Mean & Std. deviation & $p$-value \\
\hline \multirow{2}{*}{ The nature watch reserve visit was interesting } & Boy & 4.78 & 0.529 & \multirow{2}{*}{0.087} \\
\hline & Girl & 4.71 & 0.541 & \\
\hline \multirow{2}{*}{ I enjoyed the visit } & Boy & 4.80 & 0.578 & \multirow{2}{*}{0.036} \\
\hline & Girl & 4.72 & 0.527 & \\
\hline \multirow{2}{*}{ The teachers on site were good } & Boy & 4.75 & 0.579 & \multirow{2}{*}{0.514} \\
\hline & Girl & 4.79 & 0.541 & \\
\hline \multirow{2}{*}{ The materials and handouts were good } & Boy & 4.39 & 0.951 & \multirow{2}{*}{0.814} \\
\hline & Girl & 4.40 & 0.829 & \\
\hline \multirow{2}{*}{ The place was great } & Boy & 4.81 & 0.527 & \multirow{2}{*}{0.030} \\
\hline & Girl & 4.66 & 0.722 & \\
\hline \multirow{2}{*}{ I felt safe outside } & Boy & 4.19 & 1.026 & \multirow{2}{*}{0.233} \\
\hline & Girl & 4.10 & 0.973 & \\
\hline \multirow{2}{*}{ The visit helped me in school subjects } & Boy & 4.40 & 0.972 & \multirow{2}{*}{0.520} \\
\hline & Girl & 4.36 & 0.960 & \\
\hline \multirow{2}{*}{ I learned a lot in the outing } & Boy & 4.67 & 0.698 & \multirow{2}{*}{0.383} \\
\hline & Girl & 4.63 & 0.666 & \\
\hline \multirow{2}{*}{ I care more about nature following the visit } & Boy & 4.50 & 0.971 & \multirow{2}{*}{0.069} \\
\hline & Girl & 4.69 & 0.733 & \\
\hline
\end{tabular}

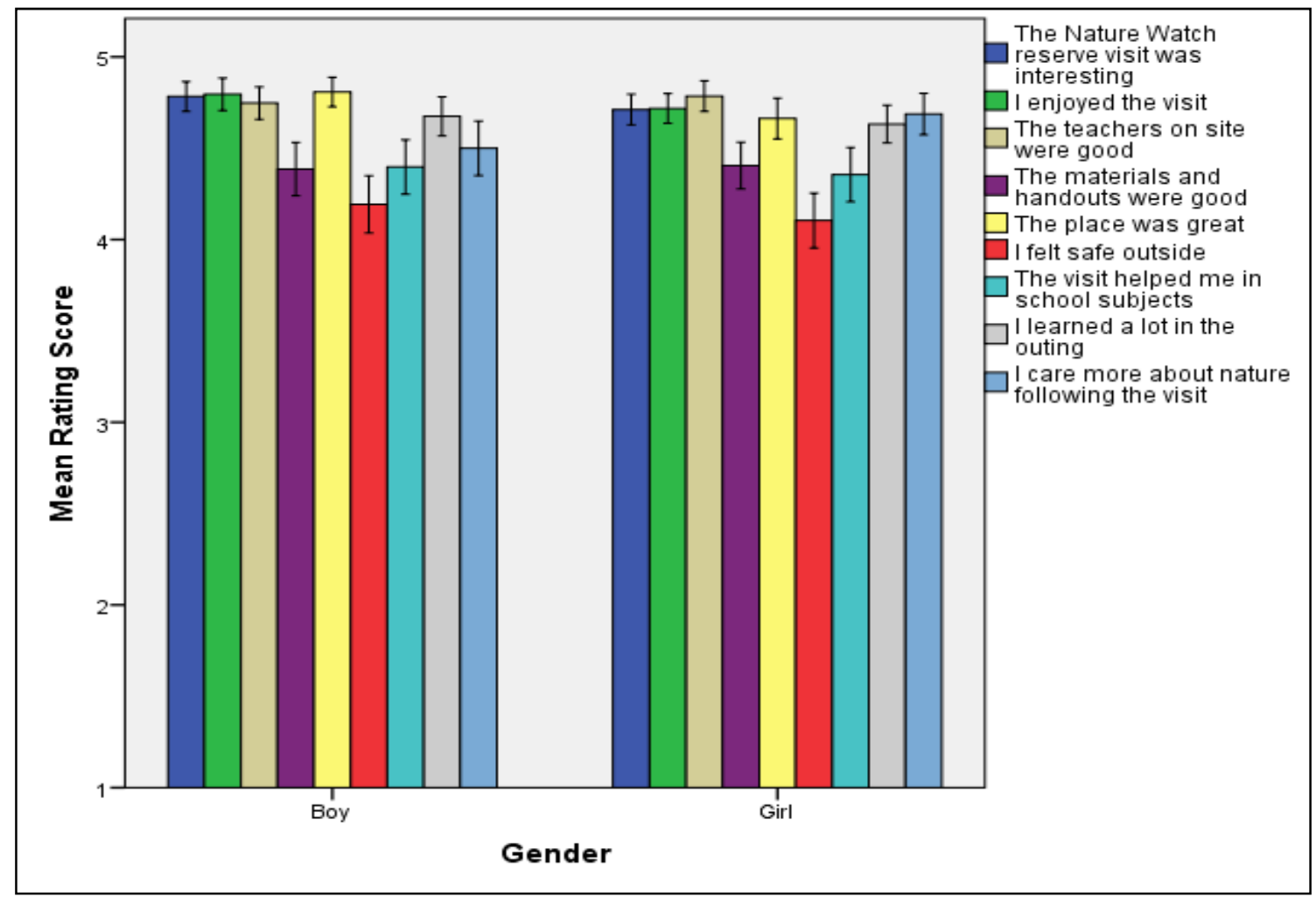

Figure 3. Nature watch reserve visit experience in male/female comparison.

The mean score from the nature watch reserve visit experience was analysed according to the geographic location of the students to identify any correlation between the two. The mean total scores for all the locations 
appear to be very positive in all the statements, but there is a sustained greater score for most statements coming from the Gozo region. Further analysis with the Kruskal Wallis test indicates that there is statistical significance for four of the statements: "The materials and handouts were good," "The visit helped me in school subjects," "I learnt a lot during the outing," and "I care more about nature following the visit" since the $p$-value (approximately $0.000,0.000,0.007$, and 0.000 , respectively) is less than the 0.05 level of significance. Therefore, the statistical test indicates a statistically significant relationship between geographic location and these four statements (see Table 14 and Figure 4).

Table 14

Nature Watch Reserve Visit Experience in Location Comparison

\begin{tabular}{|c|c|c|c|c|}
\hline Statements & Location & Mean & Std. deviation & $p$-value \\
\hline \multirow{4}{*}{ The nature watch reserve visit was interesting } & South & 4.78 & 0.534 & \multirow{4}{*}{0.091} \\
\hline & Central & 4.69 & 0.558 & \\
\hline & North & 4.79 & 0.426 & \\
\hline & Gozo & 4.91 & 0.426 & \\
\hline \multirow{4}{*}{ I enjoyed the visit } & South & 4.80 & 0.477 & \multirow{4}{*}{0.072} \\
\hline & Central & 4.68 & 0.651 & \\
\hline & North & 4.71 & 0.469 & \\
\hline & Gozo & 4.95 & 0.213 & \\
\hline \multirow{4}{*}{ The teachers on site were good } & South & 4.76 & 0.531 & \multirow{4}{*}{0.106} \\
\hline & Central & 4.75 & 0.617 & \\
\hline & North & 4.64 & 0.633 & \\
\hline & Gozo & 5.00 & 0.000 & \\
\hline \multirow{4}{*}{ The materials and handouts were good } & South & 4.52 & 0.797 & \multirow{4}{*}{0.000} \\
\hline & Central & 4.19 & 0.949 & \\
\hline & North & 4.57 & 1.089 & \\
\hline & Gozo & 4.82 & 0.664 & \\
\hline \multirow{4}{*}{ The place was great } & South & 4.77 & 0.598 & \multirow{4}{*}{0.811} \\
\hline & Central & 4.69 & 0.700 & \\
\hline & North & 4.79 & 0.426 & \\
\hline & Gozo & 4.77 & 0.528 & \\
\hline \multirow{4}{*}{ I felt safe outside } & South & 4.22 & 1.082 & \multirow{4}{*}{0.122} \\
\hline & Central & 4.10 & 0.945 & \\
\hline & North & 3.86 & 0.864 & \\
\hline & Gozo & 4.18 & 0.853 & \\
\hline \multirow{4}{*}{ The visit helped me in school subjects } & South & 4.48 & 0.924 & \multirow{4}{*}{0.000} \\
\hline & Central & 4.19 & 1.033 & \\
\hline & North & 4.29 & 0.914 & \\
\hline & Gozo & 5.00 & 0.000 & \\
\hline \multirow{4}{*}{ I learned a lot in the outing } & South & 4.72 & 0.594 & \multirow{4}{*}{0.007} \\
\hline & Central & 4.55 & 0.762 & \\
\hline & North & 4.50 & 0.941 & \\
\hline & Gozo & 5.00 & 0.000 & \\
\hline \multirow{4}{*}{ I cared more about nature following the visit } & South & 4.65 & 0.746 & \multirow{4}{*}{0.020} \\
\hline & Central & 4.54 & 0.933 & \\
\hline & North & 4.14 & 1.167 & \\
\hline & Gozo & 4.82 & 0.853 & \\
\hline
\end{tabular}




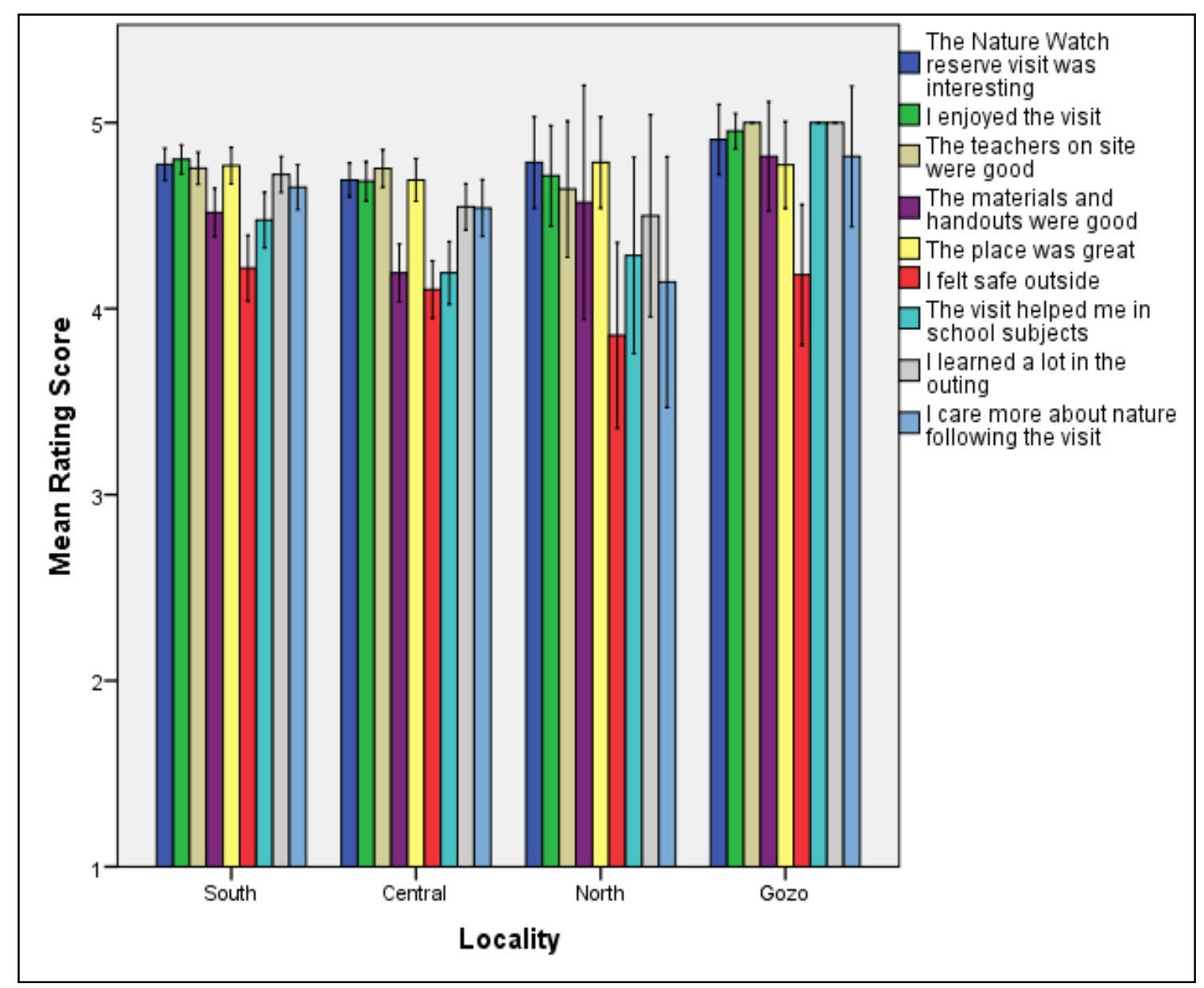

Figure 4. Nature watch reserve visit experience in location comparison.

The analysis of the age of the students to identify any correlation between the two from the nature watch reserve visit experience was same as the results of the geographic location. Both of them appear to be very positive in all the statements, but there is also statistical significance for the four statements. Therefore, the statistical test indicates a statistically significant relationship between age and these four statements (see Table 15 and Figure 5).

\section{Secondary Students}

The results from the questions that concerned the nature watch reserve visit experience for secondary students reveal that the experience was a positive one, although to a lesser extent than for the primary students, and that there are some differences in the results of the various statements. The results for secondary students indicate that "The teachers on site were good (Mean = 4.24)," "I felt safe outside (Mean = 4.11)," "The nature watch reserve visit was interesting $($ Mean $=4.10)$ " and "The place was great $($ Mean $=4.10)$," were the top scoring statements, while "Group work was good $($ Mean = 3.72)," and "Individual work was good (Mean = 3.77)" were the lowest scoring statement. The Friedman test suggests that the difference in statement score is significant and is not attributed to chance since the $p$-value (approximately 0.001 ) is less than the 0.05 level of significance (see Table 16 and Figure 6). 
Table 15

Nature Watch Reserve Visit Experience in Age comparison

\begin{tabular}{|c|c|c|c|c|}
\hline & Age & Mean & Std. deviation & $p$-value \\
\hline \multirow{5}{*}{ The nature watch reserve visit was interesting } & 7-year-old & 4.76 & 0.578 & \multirow{5}{*}{0.225} \\
\hline & 8 -year-old & 4.75 & 0.536 & \\
\hline & 9-year-old & 4.81 & 0.438 & \\
\hline & 10-year-old & 4.69 & 0.471 & \\
\hline & 11-year-old & 4.56 & 0.629 & \\
\hline \multirow{5}{*}{ I enjoyed the visit } & 7-year-old & 4.82 & 0.500 & \multirow{5}{*}{0.064} \\
\hline & 8 -year-old & 4.78 & 0.498 & \\
\hline & 9-year-old & 4.76 & 0.432 & \\
\hline & 10-year-old & 4.56 & 0.840 & \\
\hline & 11-year-old & 4.50 & 0.816 & \\
\hline \multirow{5}{*}{ The teachers on site were good } & 7-year-old & 4.82 & 0.632 & \multirow{5}{*}{0.035} \\
\hline & 8 -year-old & 4.71 & 0.551 & \\
\hline & 9-year-old & 4.81 & 0.479 & \\
\hline & 10-year-old & 4.69 & 0.471 & \\
\hline & 11-year-old & 4.75 & 0.447 & \\
\hline \multirow{5}{*}{ The materials and handouts were good } & 7-year-old & 4.59 & 0.782 & \multirow{5}{*}{0.000} \\
\hline & 8 -year-old & 4.37 & 0.919 & \\
\hline & 9-year-old & 4.50 & 0.637 & \\
\hline & 10 -year-old & 3.84 & 1.221 & \\
\hline & 11-year-old & 3.88 & 0.885 & \\
\hline \multirow{5}{*}{ The place was great } & 7-year-old & 4.79 & 0.546 & \multirow{5}{*}{0.527} \\
\hline & 8 -year-old & 4.72 & 0.673 & \\
\hline & 9-year-old & 4.74 & 0.620 & \\
\hline & 10-year-old & 4.56 & 0.840 & \\
\hline & 11-year-old & 4.75 & 0.577 & \\
\hline \multirow{5}{*}{ I felt safe outside } & 7-year-old & 4.36 & 1.032 & \multirow{5}{*}{0.000} \\
\hline & 8 -year-old & 4.18 & 0.934 & \\
\hline & 9-year-old & 3.96 & 0.910 & \\
\hline & 10 -year-old & 3.75 & 1.136 & \\
\hline & 11-year-old & 3.81 & 0.834 & \\
\hline \multirow{5}{*}{ The visit helped me in school subjects } & 7-year-old & 4.68 & 0.635 & \multirow{5}{*}{0.000} \\
\hline & 8 -year-old & 4.29 & 1.078 & \\
\hline & 9-year-old & 4.24 & 1.132 & \\
\hline & 10-year-old & 3.91 & 0.928 & \\
\hline & 11-year-old & 4.06 & 1.124 & \\
\hline \multirow{5}{*}{ I learned a lot in the outing } & 7-year-old & 4.73 & 0.658 & \multirow{5}{*}{0.041} \\
\hline & 8 -year-old & 4.68 & 0.641 & \\
\hline & 9-year-old & 4.59 & 0.813 & \\
\hline & 10-year-old & 4.44 & 0.716 & \\
\hline & 11-year-old & 4.56 & 0.512 & \\
\hline \multirow{5}{*}{ I cared more about nature following the visit } & 7-year-old & 4.64 & 0.893 & \multirow{5}{*}{0.336} \\
\hline & 8-year-old & 4.53 & 0.842 & \\
\hline & 9-year-old & 4.63 & 0.896 & \\
\hline & 10 -year-old & 4.56 & 0.716 & \\
\hline & 11-year-old & 4.56 & 1.031 & \\
\hline
\end{tabular}




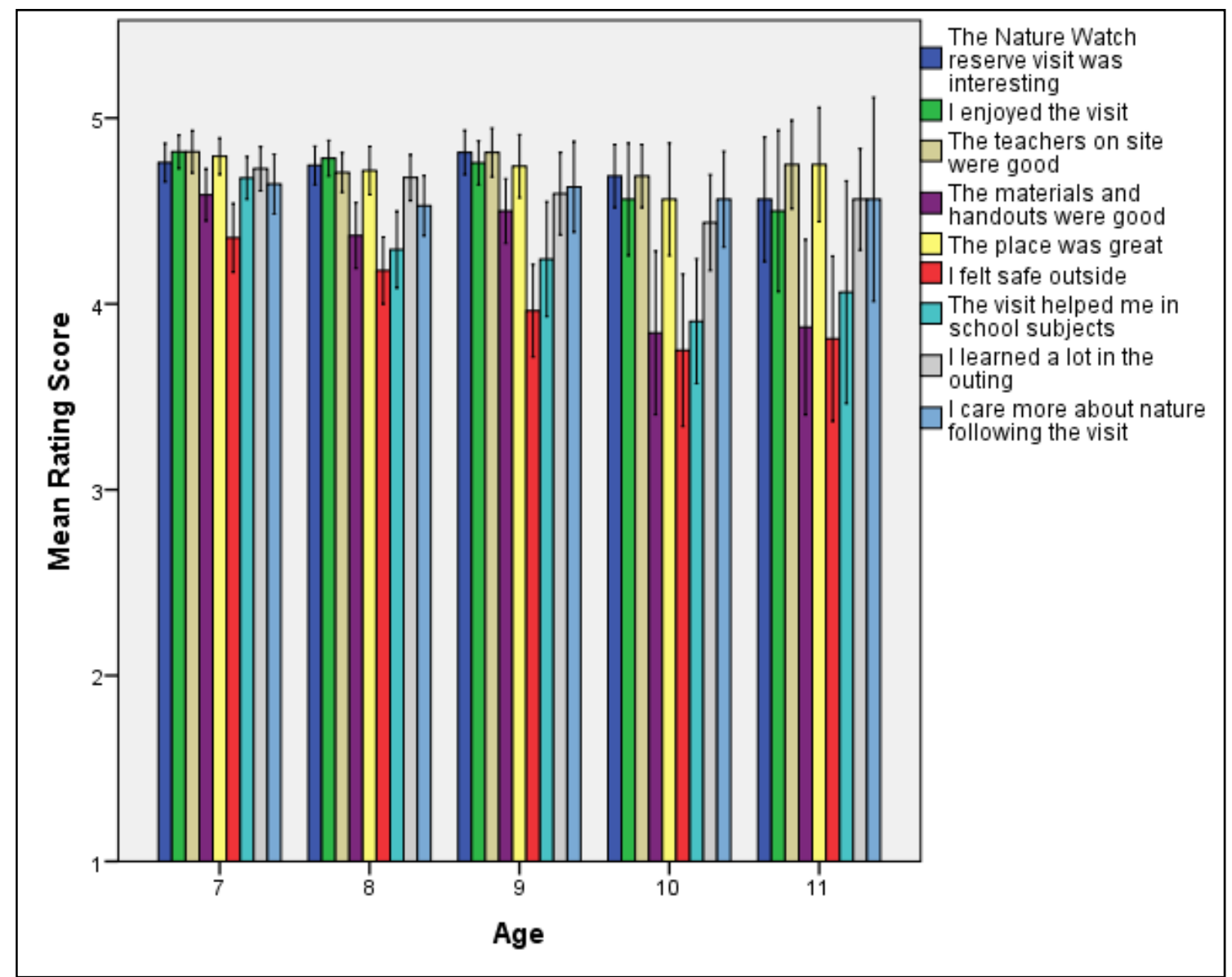

Figure 5. Nature watch reserve visit experience in age comparison.

Table 16

Nature Watch Reserve Visit Experience for Secondary Students

\begin{tabular}{lll}
\hline Statements & Mean & Std. deviation \\
\hline The nature watch reserve visit was interesting & 4.10 & 0.853 \\
I enjoyed the reserve visit & 3.96 & 0.911 \\
The teachers on the site were good & 4.24 & 0.795 \\
The materials and handouts were good & 4.09 & 0.854 \\
The place was great & 4.10 & 0.892 \\
I felt safe outside & 4.11 & 0.974 \\
The reserve visit helped me in some school subjects & 3.94 & 0.963 \\
I learnt a lot in the outing & 4.00 & 0.931 \\
Group work was good & 3.72 & 1.041 \\
Individual work was good & 3.77 & 1.023 \\
I cared more about nature following the visit & 3.95 & 1.003 \\
\hline
\end{tabular}

Notes. $X^{2}(10)=97.90 ; p<0.001$. 


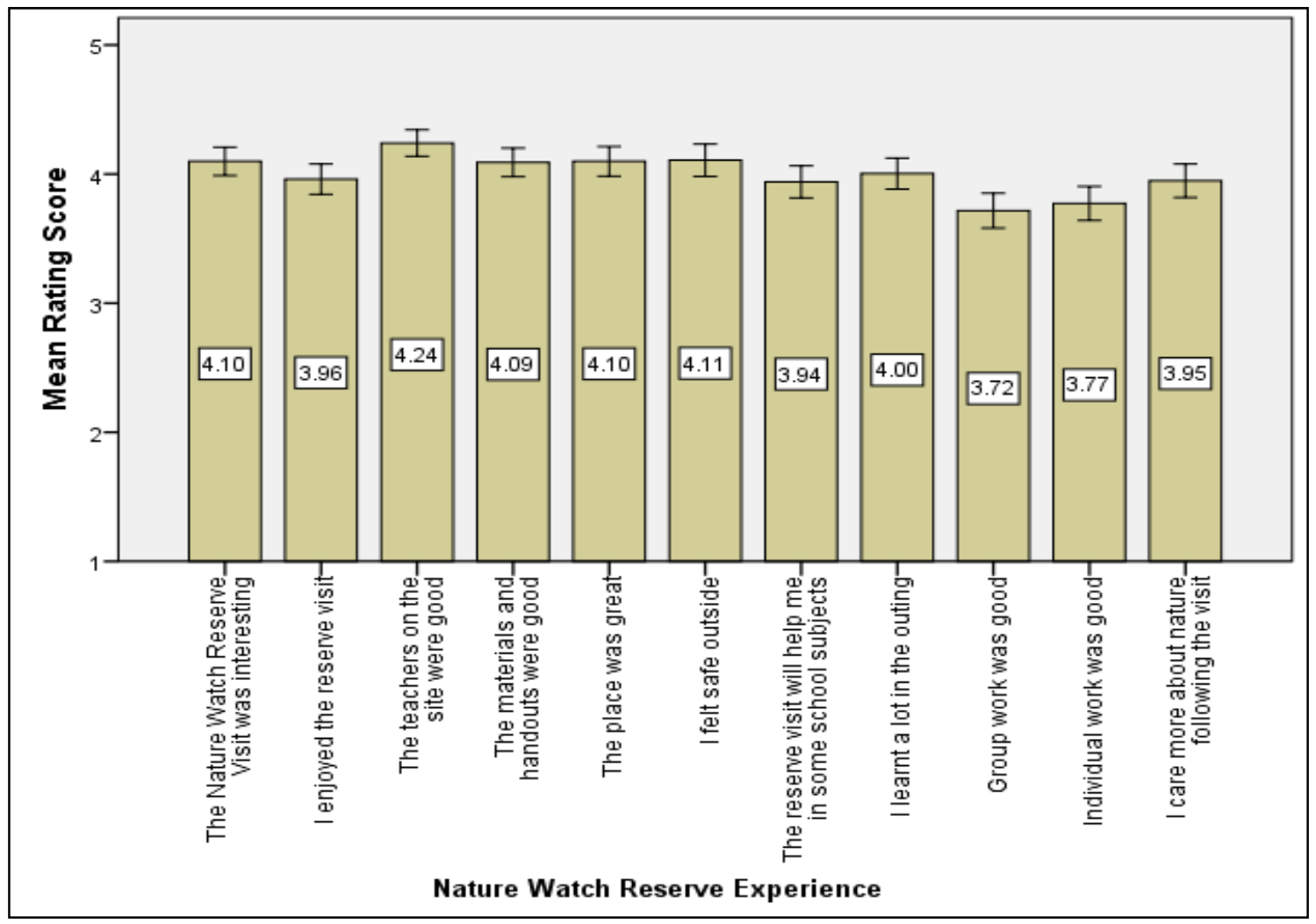

Figure 6. Nature watch reserve visit experience for secondary students.

The mean score from the nature watch reserve visit experience was analysed according to the gender of the young people population to identify any correlation between the two. The mean total scores for females and males appear to be both very positive in all the statements, but in nearly all statements the mean for males is more than the mean for females. Further analysis with the Kruskal Wallis test indicates that for most of the statements there is no statistical significance between genders. However, the test indicates statistical significance for one statement - I enjoyed the visit, since the $p$-value (0.034) is less than the 0.05 level of significance. Therefore, the statistical test indicates a statistically significant relationship between gender and this statement, suggesting that males enjoyed the visit more than females. This trend was also statistically significant with the primary school students (see Table 17 and Figure 7).

The mean score from the nature watch reserve visit experience was analysed according to the age of the students to identify any correlation between the two. The mean total scores for all the ages appear to be very positive in all the statements (at a lesser extent that the primary students), but there is an apparent decrease in scores in most of the statements as student age increases. Further analysis with the Kruskal Wallis test indicates that there is statistical significance for eight of the statements: "The nature watch reserve visit was interesting," "I enjoyed the nature watch reserve visit," "The teachers on the site were good," "The materials and handouts were good," "The place was great," "The visit will help me in school subjects," "I leant a lot during the outing," and "I cared more about nature following the visit" since the $p$-value (approximately $0.000,0.000,0.0033,0.005,0.003$, $0.034,0.022$, and 0.012 , respectively) is less than the 0.05 level of significance. Therefore, the statistical test indicates a statistically significant relationship between age and these eight statements. It is clear that younger students are more engaged at a higher level in the outing than older students (see Table 18 and Figure 8). 
Table 17

Nature Watch Reserve Visit Experience in Male/Female Comparison

\begin{tabular}{|c|c|c|c|c|c|}
\hline Statements & Gender & $N$ & Mean & Std. deviation & $p$-value \\
\hline \multirow{2}{*}{ The nature watch reserve visit was interesting } & Boy & 86 & 4.23 & 0.730 & \multirow{2}{*}{0.105} \\
\hline & Girl & 147 & 4.02 & 0.910 & \\
\hline \multirow{2}{*}{ I enjoyed the reserve visit } & Boy & 86 & 4.14 & 0.754 & \multirow{2}{*}{0.034} \\
\hline & Girl & 147 & 3.86 & 0.979 & \\
\hline \multirow{2}{*}{ The teachers on the site were good } & Boy & 86 & 4.33 & 0.710 & \multirow{2}{*}{0.305} \\
\hline & Girl & 147 & 4.19 & 0.839 & \\
\hline \multirow{2}{*}{ The materials and handouts were good } & Boy & 86 & 3.99 & 0.790 & \multirow{2}{*}{0.063} \\
\hline & Girl & 147 & 4.15 & 0.886 & \\
\hline \multirow{2}{*}{ The place was great } & Boy & 86 & 4.23 & 0.836 & \multirow{2}{*}{0.068} \\
\hline & Girl & 147 & 4.02 & 0.918 & \\
\hline \multirow{2}{*}{ I felt safe outside } & Boy & 86 & 4.15 & 1.023 & \multirow{2}{*}{0.374} \\
\hline & Girl & 147 & 4.08 & 0.947 & \\
\hline \multirow{2}{*}{ The visit helped me in some school subjects } & Boy & 86 & 4.03 & 0.939 & \multirow{2}{*}{0.251} \\
\hline & Girl & 147 & 3.88 & 0.976 & \\
\hline \multirow{2}{*}{ I learnt a lot in the outing } & Boy & 86 & 4.05 & 0.957 & \multirow{2}{*}{0.441} \\
\hline & Girl & 147 & 3.98 & 0.918 & \\
\hline \multirow{2}{*}{ Group work was good } & Boy & 86 & 3.72 & 1.134 & \multirow{2}{*}{0.754} \\
\hline & Girl & 147 & 3.71 & 0.986 & \\
\hline \multirow{2}{*}{ Individual work was good } & Boy & 86 & 3.94 & 0.962 & \multirow{2}{*}{0.060} \\
\hline & Girl & 147 & 3.67 & 1.048 & \\
\hline \multirow{2}{*}{ I cared more about nature following the visit } & Boy & 86 & 4.06 & 1.022 & \multirow{2}{*}{0.131} \\
\hline & Girl & 147 & 3.88 & 0.990 & \\
\hline
\end{tabular}

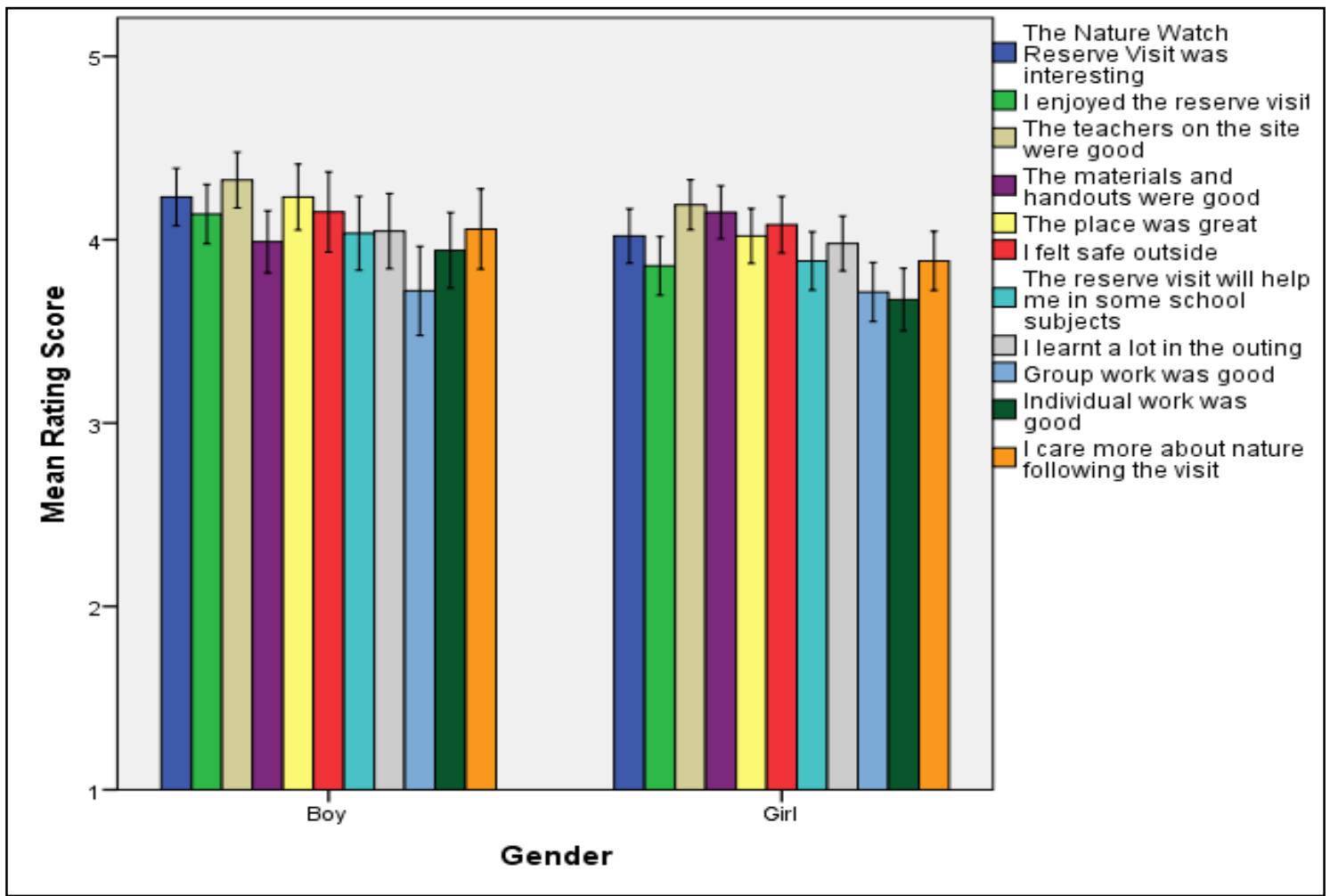

Figure 7. Nature watch reserve visit experience in male/female comparison. 
Table 18

Nature Watch Reserve Visit Experience in Age Comparison

\begin{tabular}{|c|c|c|c|c|c|}
\hline Statements & Age & $N$ & Mean & Std. deviation & $p$-value \\
\hline \multirow{5}{*}{$\begin{array}{l}\text { The nature watch reserve visit was } \\
\text { interesting }\end{array}$} & 11-year-old & 23 & 4.74 & 0.449 & \multirow{5}{*}{0.000} \\
\hline & 12-year-old & 29 & 4.38 & 0.677 & \\
\hline & 13-year-old & 38 & 4.13 & 1.018 & \\
\hline & 14-year-old & 84 & 3.98 & 0.776 & \\
\hline & 15- and16- year-old & 59 & 3.86 & 0.899 & \\
\hline \multirow{5}{*}{ I enjoyed the reserve visit } & 11-year-old & 23 & 4.70 & 0.470 & \multirow{5}{*}{0.000} \\
\hline & 12-year-old & 29 & 4.38 & 0.561 & \\
\hline & 13-year-old & 38 & 4.08 & 1.100 & \\
\hline & 14-year-old & 84 & 3.81 & 0.784 & \\
\hline & 15- and16- year-old & 59 & 3.61 & 0.983 & \\
\hline \multirow{5}{*}{ The teachers on the site were good } & 11-year-old & 23 & 4.61 & 0.583 & \multirow{5}{*}{0.033} \\
\hline & 12-year-old & 29 & 4.41 & 0.628 & \\
\hline & 13-year-old & 38 & 4.26 & 0.860 & \\
\hline & 14-year-old & 84 & 4.07 & 0.847 & \\
\hline & 15- and16- year-old & 59 & 4.24 & 0.773 & \\
\hline \multirow{5}{*}{ The materials and handouts were good } & 11-year-old & 23 & 4.65 & 0.487 & \multirow{5}{*}{0.005} \\
\hline & 12-year-old & 29 & 4.10 & 0.724 & \\
\hline & 13-year-old & 38 & 3.84 & 0.973 & \\
\hline & 14-year-old & 84 & 4.04 & 0.842 & \\
\hline & 15- and16- year-old & 59 & 4.10 & 0.885 & \\
\hline \multirow{5}{*}{ The place was great } & 11-year-old & 23 & 4.52 & 0.846 & \multirow{5}{*}{0.003} \\
\hline & 12-year-old & 29 & 4.31 & 0.604 & \\
\hline & 13-year-old & 38 & 4.16 & 1.027 & \\
\hline & 14-year-old & 84 & 4.05 & 0.890 & \\
\hline & 15- and16- year-old & 59 & 3.86 & 0.880 & \\
\hline \multirow{5}{*}{ I felt safe outside } & 11-year-old & 23 & 4.43 & 0.590 & \multirow{5}{*}{0.114} \\
\hline & 12-year-old & 29 & 4.41 & 0.733 & \\
\hline & 13-year-old & 38 & 4.03 & 1.262 & \\
\hline & 14-year-old & 84 & 3.95 & 0.968 & \\
\hline & 15- and16- year-old & 59 & 4.10 & 0.959 & \\
\hline \multirow{5}{*}{ The visit helped me in some school subjects } & 11-year-old & 23 & 4.52 & 0.665 & \multirow{5}{*}{0.034} \\
\hline & 12-year-old & 29 & 3.79 & 1.048 & \\
\hline & 13-year-old & 38 & 3.82 & 1.205 & \\
\hline & 14-year-old & 84 & 3.88 & 0.884 & \\
\hline & 15- and16- year-old & 59 & 3.95 & 0.899 & \\
\hline \multirow{5}{*}{ I learnt a lot in the outing } & 11-year-old & 23 & 4.48 & 0.665 & \multirow{5}{*}{0.022} \\
\hline & 12-year-old & 29 & 4.24 & 0.951 & \\
\hline & 13-year-old & 38 & 3.92 & 1.124 & \\
\hline & 14-year-old & 84 & 3.88 & 0.937 & \\
\hline & 15- and16- year-old & 59 & 3.93 & 0.807 & \\
\hline \multirow{5}{*}{ Group work was good } & 11-year-old & 23 & 4.13 & 0.920 & \multirow{5}{*}{0.126} \\
\hline & 12-year-old & 29 & 3.55 & 1.298 & \\
\hline & 13-year-old & 38 & 3.89 & 0.981 & \\
\hline & 14-year-old & 84 & 3.65 & 0.963 & \\
\hline & 15- and16- year-old & 59 & 3.61 & 1.067 & \\
\hline
\end{tabular}


(Table 18 to be continued)

\begin{tabular}{|c|c|c|c|c|c|}
\hline \multirow{5}{*}{ Individual work was good } & 11-year-old & 23 & 3.91 & 1.041 & \multirow{5}{*}{0.831} \\
\hline & 12-year-old & 29 & 3.76 & 0.872 & \\
\hline & 13-year-old & 38 & 3.68 & 1.188 & \\
\hline & 14-year-old & 84 & 3.69 & 1.053 & \\
\hline & 15- and16-year-old & 59 & 3.90 & 0.941 & \\
\hline \multirow{5}{*}{ I cared more about nature following the visit } & 11-year-old & 23 & 4.48 & 0.665 & \multirow{5}{*}{0.012} \\
\hline & 12-year-old & 29 & 4.10 & 0.900 & \\
\hline & 13-year-old & 38 & 4.03 & 1.078 & \\
\hline & 14-year-old & 84 & 3.86 & 1.110 & \\
\hline & 15- and16- year-old & 59 & 3.75 & 0.883 & \\
\hline
\end{tabular}

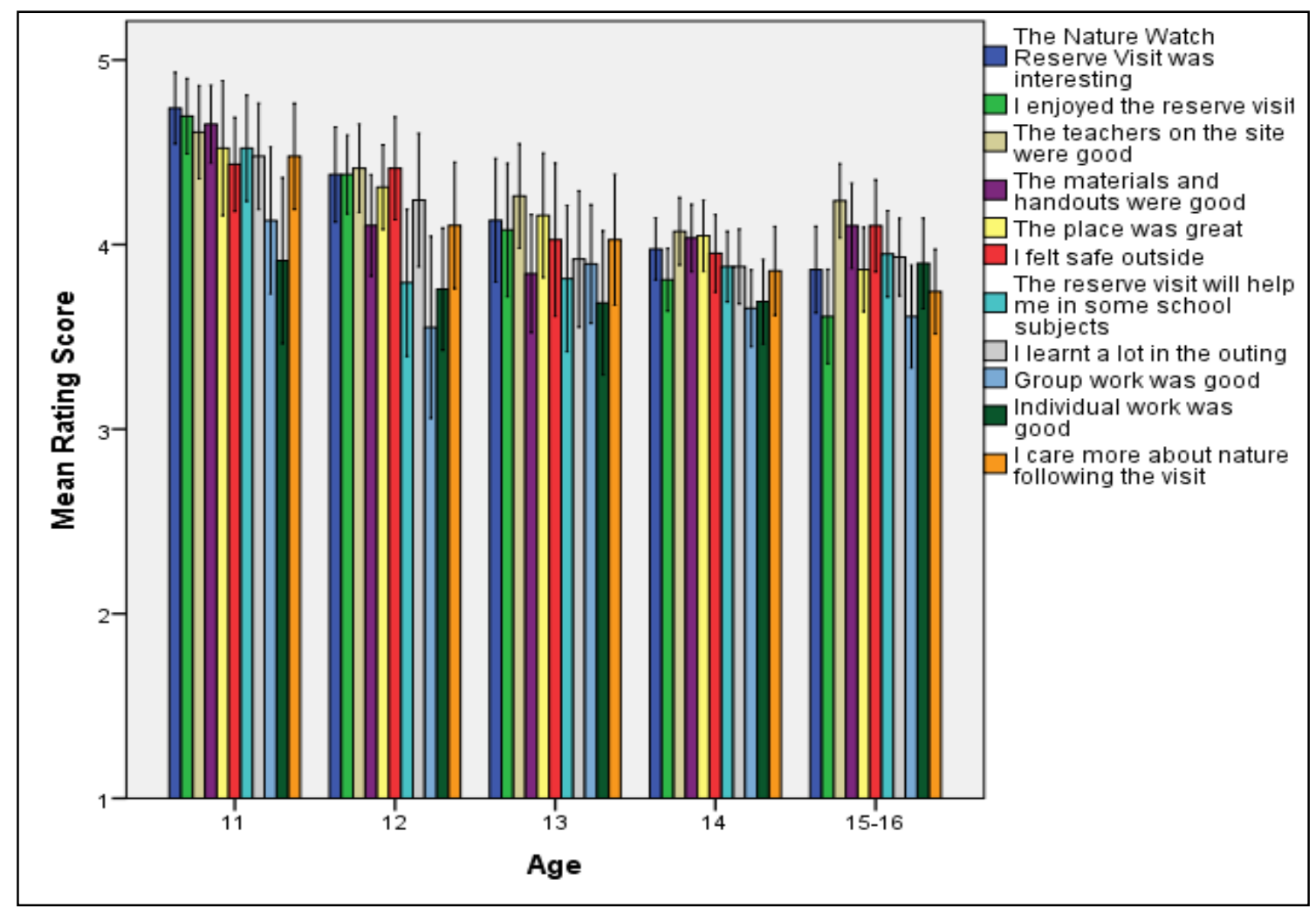

Figure 8. Nature watch reserve visit experience in age comparison.

The mean score from the nature watch reserve visit experience was analysed according to the geographic location of the students to identify any correlation between the two. The mean total scores for all the locations appear to be very positive in all the statements, but there is a sustained greater score for most statements coming from the Gozo region and a sustained low score for most statements from the Northern region. Further analysis with the Kruskal Wallis test indicates that there is statistical significance for seven statements: "The nature watch reserve visit was interesting," "I enjoyed the reserve visit," "The teachers on the site were good," "The place was great," "I leant a lot during the outing," "Group work was good," and "I care more about nature following the visit" since the $p$-value (approximately $0.005,0.004,0.028,0.017,0.028,0.002$, and 0.035 , respectively) is less than the 0.05 level of significance. Therefore, the statistical test indicates a statistically significant relationship between geographic location and these seven statements (see Table 19 and Figure 9). 
Table 19

Nature Watch Reserve Visit Experience in Locality Comparison

\begin{tabular}{|c|c|c|c|c|c|}
\hline Statements & Locality & $N$ & Mean & Std. deviation & $p$-value \\
\hline \multirow{4}{*}{ The nature watch reserve visit was interesting } & South & 105 & 4.17 & 0.904 & \multirow{4}{*}{0.005} \\
\hline & Central & 76 & 3.92 & 0.845 & \\
\hline & North & 18 & 3.83 & 0.857 & \\
\hline & Gozo & 24 & 4.46 & 0.509 & \\
\hline \multirow{4}{*}{ I enjoyed the reserve visit } & South & 105 & 4.06 & 0.959 & \multirow{4}{*}{0.004} \\
\hline & Central & 76 & 3.72 & 0.961 & \\
\hline & North & 18 & 3.78 & 0.808 & \\
\hline & Gozo & 24 & 4.38 & 0.495 & \\
\hline \multirow{4}{*}{ The teachers on the site were good } & South & 105 & 4.25 & 0.818 & \multirow{4}{*}{0.028} \\
\hline & Central & 76 & 4.16 & 0.834 & \\
\hline & North & 18 & 3.94 & 0.725 & \\
\hline & Gozo & 24 & 4.58 & 0.584 & \\
\hline \multirow{4}{*}{ The materials and handouts were good } & South & 105 & 4.10 & 0.876 & \multirow{4}{*}{0.215} \\
\hline & Central & 76 & 4.14 & 0.860 & \\
\hline & North & 18 & 3.72 & 0.826 & \\
\hline & Gozo & 24 & 4.21 & 0.721 & \\
\hline \multirow{4}{*}{ The place was great } & South & 105 & 4.10 & 1.005 & \multirow{4}{*}{0.017} \\
\hline & Central & 76 & 4.04 & 0.824 & \\
\hline & North & 18 & 3.83 & 0.857 & \\
\hline & Gozo & 24 & 4.54 & 0.509 & \\
\hline \multirow{4}{*}{ I felt safe outside } & South & 105 & 4.08 & 1.016 & \multirow{4}{*}{0.482} \\
\hline & Central & 76 & 4.13 & 0.998 & \\
\hline & North & 18 & 3.83 & 1.043 & \\
\hline & Gozo & 24 & 4.29 & 0.806 & \\
\hline \multirow{4}{*}{ The visit helped me in some school subjects } & South & 105 & 3.93 & 1.103 & \multirow{4}{*}{0.151} \\
\hline & Central & 76 & 3.91 & 0.836 & \\
\hline & North & 18 & 3.72 & 0.826 & \\
\hline & Gozo & 24 & 4.29 & 0.806 & \\
\hline \multirow{4}{*}{ I learnt a lot in the outing } & South & 105 & 4.05 & 1.013 & \multirow{4}{*}{0.028} \\
\hline & Central & 76 & 3.86 & 0.875 & \\
\hline & North & 18 & 3.94 & 0.938 & \\
\hline & Gozo & 24 & 4.46 & 0.658 & \\
\hline \multirow{4}{*}{ Group work was good } & South & 105 & 3.62 & 1.121 & \multirow{4}{*}{0.002} \\
\hline & Central & 76 & 3.79 & 0.957 & \\
\hline & North & 18 & 3.17 & 0.924 & \\
\hline & Gozo & 24 & 4.29 & 0.690 & \\
\hline \multirow{4}{*}{ Individual work was good } & South & 105 & 3.71 & 1.107 & \multirow{4}{*}{0.114} \\
\hline & Central & 76 & 3.70 & 0.966 & \\
\hline & North & 18 & 3.67 & 1.138 & \\
\hline & Gozo & 24 & 4.25 & 0.737 & \\
\hline \multirow{4}{*}{ I care more about nature following the visit } & South & 105 & 4.04 & 0.970 & \multirow{4}{*}{0.035} \\
\hline & Central & 76 & 3.79 & 1.011 & \\
\hline & North & 18 & 3.56 & 1.247 & \\
\hline & Gozo & 24 & 4.33 & 0.868 & \\
\hline
\end{tabular}




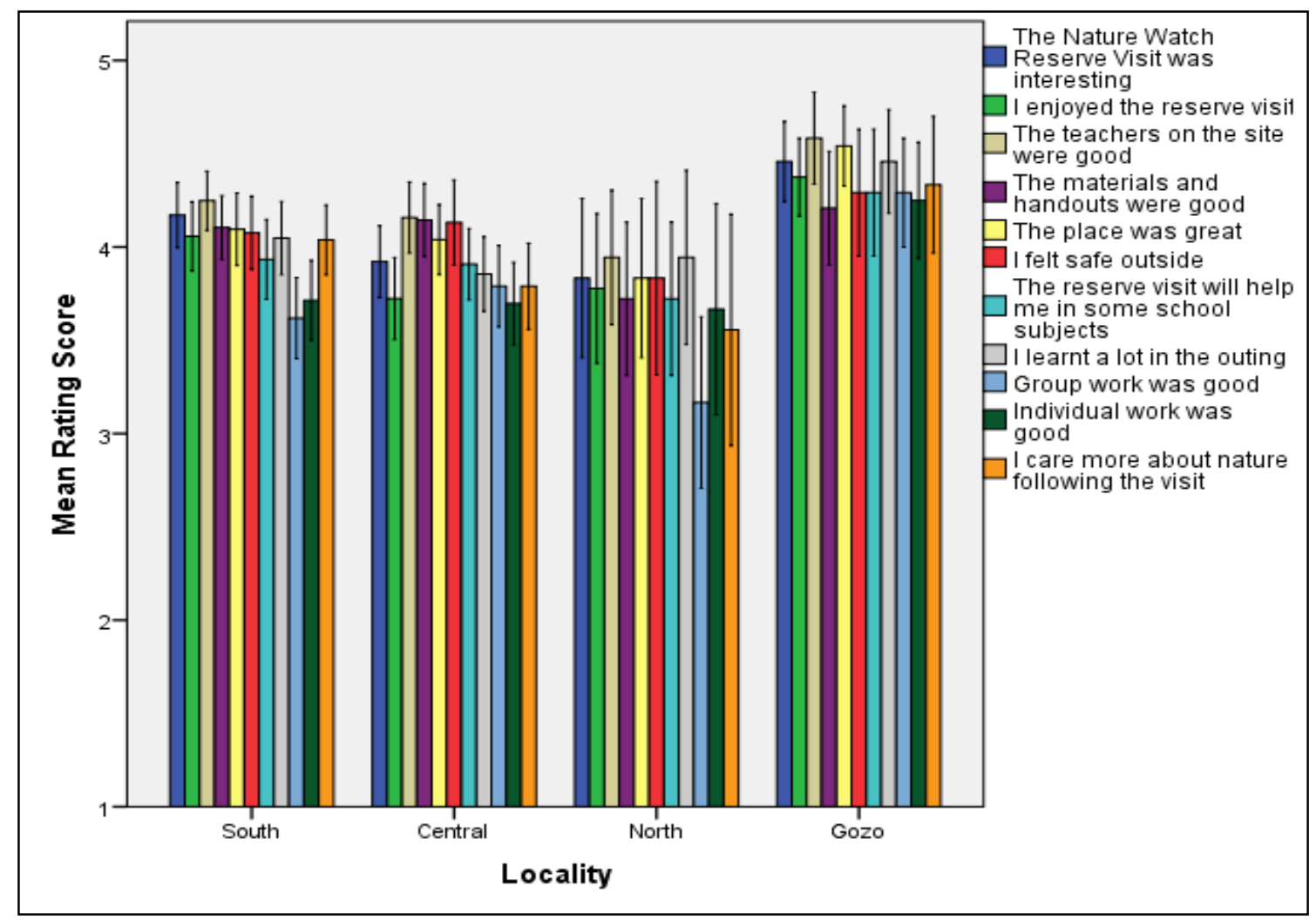

Figure 9. Nature watch reserve visit experience in locality comparison.

"I increase my knowledge (77.8\% for boys and $69.5 \%$ for girls)" and "I care about the environment (54.3\% for boys and $59.6 \%$ for girls)" were mentioned as the most important reasons for taking part in the Nature Reserve visit. There are significant differences to the statement "To make more friends $(3.7 \%$ for boys and $9.2 \%$ for girls)." Girls appear to afford more importance to the collective social aspect than boys. Moreover, an important aspect for boys appears to be the fun factor with $53.1 \%$ choosing the statement "I have fun" when compared to $36.2 \%$ for girls.

The remaining statements have very comparable results from both boys and girls and generally have very low reply rates. These include statements that involved some sort of achievement or competition, such as "I like to receive an award ( $6.2 \%$ for boys and $8.5 \%$ for girls)." Another low scoring statement includes "Because of my values $(6.2 \%$ for boys and $7.8 \%$ for girls)," which contrasts with the other value statement involved "Because I care for the environment (54.3\% for boys and 59.6\% for girls)," possibly indicating lack of proper understanding of the more abstract terms like values (see Table 20 and Figure 10).

Table 20

The Best Part of the Programme in Male/Female Comparison

\begin{tabular}{llll}
\hline \multirow{2}{*}{ Statements } & & \multicolumn{2}{c}{ Gender } \\
\cline { 3 - 4 } I like to receive an award & Count & 5 & Girl \\
& Percentage (\%) & 6.2 & 12 \\
I increase my knowledge & Count & 63 & 8.5 \\
& Percentage (\%) & 77.8 & 98 \\
\hline
\end{tabular}


(Table 20 to be continued)

\begin{tabular}{llll}
\hline Because of my values & Count & 5 & 11 \\
& Percentage (\%) & 6.2 & 7.8 \\
To do better in school subjects & Count & 29 & 59 \\
& Percentage (\%) & 35.8 & 41.8 \\
I care about the environment & Count & 44 & 84 \\
& Percentage (\%) & 54.3 & 59.6 \\
I love the activities & Count & 23 & 40 \\
& Percentage (\%) & 28.4 & 51 \\
I have fun & Count & 43 & 36.2 \\
To make more friends & Percentage (\%) & 53.1 & 13 \\
To achieve more as a class & Count & 3 & 9.2 \\
To achieve more as a school & Percentage (\%) & 3.7 & 32 \\
& Count & 9 & 22.7 \\
\hline
\end{tabular}

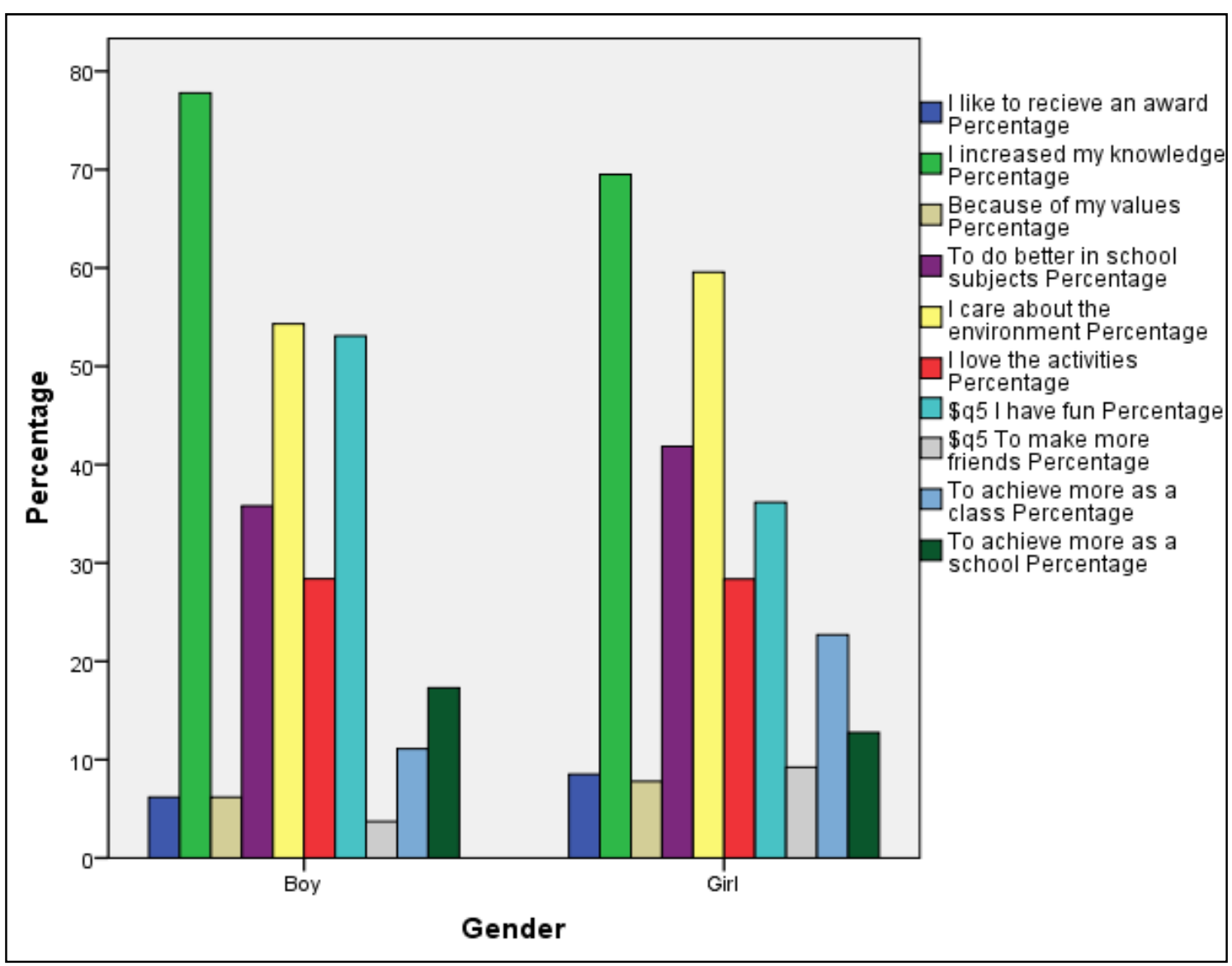

Figure 10. Nature watch reserve visit experience in male/female comparison.

\section{Conclusions and Recommendations}

The programme appears to be having a positive effect on students and is definitely a worthwhile experience for all the participants involved. Additionally, it is clearly having an effect on both environmental 
knowledge and environmental attitudes to a different extent. A number of recommendations can be found throughout the text of this report when the results are focused on a particular issue and warrant such a response. The following are general recommendations for the further improvement of the programme:

1. Ensuring that the potential of this activity to become a significant life experience is achieved through better streamling of the activities according to age, locality, and gender;

2. One day is not enough. Either increase the number of outings or even better consider spreading the outing on two days;

3. Increase curricular links wth more varied topics especialy for secondary students;

4. Improved logistics to cater for younger students;

5. More physical resources to be divided by fewer students;

6. Increase links between the natural world, the social world, and the economic one in the experience as a whole;

7. Increase the variety of activities to cater for different interests. A special focus on games especially with the younger students and an increased focus on hands on activities;

8. Ongoing monitoring and data collection to be fed to the programme in an effort to continuously improve in a dynamic world.

\section{References}

Bynoe, P. (2005). Keynote address on sustainable livelihoods to the commonwealth youth forum. St. Pual's Bay, Malta: Suncrest Hotel.

Connell, S. (1997). Empirical-analytical methodological research in environmental education: Response to a negative trend in methodological and ideological discussions. Environmental Education Research, 2(3), 117-132.

Gough A., (1999). Kids do not like wearing the same jeans as their mums and dads: So whose life should be in significant life experience research? Environmental Education Research, 4(5), 383-394.

Government of Malta. (2005). Government census. Valletta, Malta.

Mifsud, M. (2011). An investigation on the environmental knowledge, attitudes and behaviour of Maltese youth. US-China Education Review B, 1(3), 413-422.

Mifsud, M. (2012). A contextual study of the events that have shaped the development of environmental education in Malta. Journal of Teacher Education for Sustainability, 12(2), 110-128.

Mifsud, M., \& Verret, M. (2015). Perceptions of the Maltese public towards local Marine protected areas. Journal of Teacher Education for Sustainability, 17(1), 48-57.

Pawlowski, A. (1996). Perception of environmental problems by young people in Poland. Environmental Education Research, $3(2), 279-285$.

Thapa, B. (2001). Environmental concern: A comparative analysis between students in recreation and park management and other departments. Environmental Education Research, 1(7), 39-53.

United Nations Conference on Environment and Development (UNCED). (1992). Agenda 21: Programme of action for sustainable development. United Nations, N.Y.: Rio Declaration on Environment and Development. 